\title{
Ideias estéticas e imaginação poética em Hölderlin ${ }^{1}$
}

\section{Ulisses Razzante Vaccari}

Professor do departamento de filosofia na Universidade Federal de Mato Grosso do Sul

(UFMS)

1 O presente artigo é uma versão modificada de um capítulo de minha tese de doutorado. Os textos de Hölderlin citados seguem a edição Sämtliche Werke und Briefe (indicada pela sigla SW), estabelecida por Jochen Schmidt em 3 volumes; são indicados por meio de siglas dos títulos originais, seguidas do número do volume e do número da página em que se encontram nessa edição, conforme segue: HJ - Hyperions Jugend (A juventude de Hipérion); UGF - Über das Gesetzt der Freiheit (Sobre a lei da liberdade). Os textos de Schiller citados seguem a edição Theoretische Schriften (indicada pela sigla TS), estabelecida por Rolf-Peter Janz; são igualmente indicados por meio de siglas dos títulos originais, seguidas do número do volume e do número da página em que se encontram nessa edição, conforme segue: AW - Über Anmut und Würde (Sobre graça e dignidade); KS - Kallias, oder über die Schönheit (Cálias, ou sobre a beleza). Com exceção da tradução brasileira do Hipérion (que é citado pela sigla HEG) e do texto Do sublime, todos os textos de Hölderlin e de Schiller citados neste artigo foram traduzidos por mim. A lista completa das referências pode ser consultada ao final do texto.

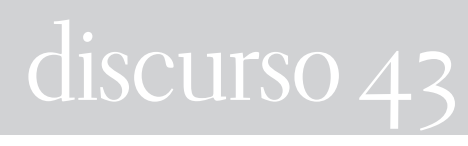



Manifestada incontáveis vezes em sua correspondência desde os tempos de Maulbronn, em $1787^{1}$, até o começo de 1800 , quando chega ao fim sua estadia em Bad Homburg², a admiração de Hölderlin por Schiller jamais passou desapercebida pelos seus leitores 3 . Um exemplo bastante convincente dessa admiração, que não tem por base apenas a produção poética e dramática, mas também os textos estético-teóricos de Schiller, pode ser lido numa carta a Neuffer de abril de 1794. Ao mencionar ao amigo e confidente estar preocupado com o estado de saúde de Schiller, Hölderlin não esconde seu entusiasmo pelo recém-publicado ensaio Sobre graça e dignidade:

Schiller está doente? A notícia me deixou muito triste. [...] Minha última leitura foi o ensaio de Schiller sobre Graça e Dignidade. Não me recordo de ter lido algo desse tipo, em que o melhor do reino do pensamento e da região da sensação e da fantasia tivessem se amalgamado em um elemento único (SW III, p.132-3).

Tendo sido pessoalmente apresentados por Gotthold Friedrich Stäudlin em 1793, Schiller e Hölderlin passam a trocar correspondências a partir de então. Em 1794, Schiller indica o então jovem poeta para trabalhar como preceptor na casa de Charlotte von Kalb, em Waltershausen, logo após ter se formado em filosofia e teologia no Instituto de Tübingen. Como assinalam os comentadores ${ }^{4}$, esse ano de 1794 em Waltershausen foi particu-

1 Cf., por exemplo, carta a Immanuel Nast de 18 de fevereiro de 1787 (SW III, p. 18), em que Hölderlin usa a expressão den feurigen Schiller (o ardente Schiller) e carta ao irmão Karl de setembro de 1793 (SW III, p. 105-6), em que Hölderlin menciona entusiasmado o Don Carlos.

2 A última carta de Hölderlin a Schiller é de 2 de junho de 1801 (in: SW III, p. 452-4). 3 Sobre a relação de Hölderlin com Schiller, cf. principalmente Beissner, F. Hölderlins Hymne an das Schicksal, 1969, p. 15-30.

4 Cf., por exemplo, Henrich, D. Der Grund im Bewu tsein, 1992, p. 266-85. Segundo o comentador, foi nesse ano que Hölderlin desenvolveu o núcleo de seu romance Hipérion ou o Eremita na Grécia. 
larmente importante para o desenvolvimento do pensamento estético-teórico de Hölderlin. O trabalho de preceptor na casa dos von Kalb, afinal, permitiu a Hölderlin dedicar-se quase que integralmente ao estudo de assuntos de seu interesse, que se dividia entre leituras da Crítica da faculdade do juízo de Kant e os gregos ${ }^{5}$, em especial a filosofia de Platão. Como se viu acima, também nesse ano Hölderlin leu o ensaio de Schiller Sobre graça e dignidade, aquilo que o colocou em sintonia com o que estava sendo produzido naquele período no campo da estética. Não por acaso, algum tempo depois, o poeta revelava ao mesmo Neuffer, em 10 de outubro de 1794, sentir-se plenamente habilitado a criar algo de novo nesse campo:

Talvez eu possa enviar-te um texto sobre as ideias estéticas, pois ele pode valer como comentário sobre o Fedro de Platão [...]. No fundamental, ele deve conter uma análise sobre o belo e o sublime, que simplifica a análise kantiana e, por outro lado, a vê de múltiplas formas, como Schiller fez em parte em seu escrito Sobre graça e dignidade, embora não tenha dado um passo para além do limite kantiano, como, em minha opinião, ele deveria ter ousado (SW III, p.157).

Hölderlin anuncia aqui a Neuffer um texto próprio sobre as ideias estéticas, ponto central da Crítica da faculdade do juízo de Kant no que se refere à fundamentação filosófica da poesia ${ }^{6}$. Esse texto, em suas palavras, atuaria em duas frentes: poderia valer "como um comentário sobre o Fedro de Platão" e conteria uma

5 Segundo consta no certificado de conclusão dos estudos em Tübingen, Hölderlin se dedicou "infatigavelmente à filologia, particularmente dos gregos, e à filosofia, em especial a kantiana, assim como à elegante literatura" (SW III, p. 618). A importância de Kant para sua formação é notada também numa carta ao irmão de 21 de maio de 1794: "minha única leitura agora é praticamente Kant. Cada vez mais esse maravilhoso espírito se revela para mim" (SW III, p.138). Ainda numa outra carta: "naquilo que se refere às investigações científicas, divido-me agora apenas entre a filosofia kantiana e os gregos, e procuro também por vezes produzir algo de propriamente meu" (SW III, p. 140).

6 Cf. Kant, I. Crítica da faculdade do juízo, 1998, p. 218-225 (B 192-202). 
análise simplificada sobre o belo e o sublime. No que se refere a esse último ponto, Hölderlin atesta que sua análise seria feita à maneira do texto de Schiller Sobre graça e dignidade, embora pretendesse ousar algo que este não havia feito em seu escrito: dar um passo além do limite kantiano. Entre outras coisas, isso indica que, desde aquela declaração a Neuffer de abril de 1794, Hölderlin trabalhou intensamente em seu projeto, de modo que, agora, em outubro, suas bases estariam praticamente estabelecidas. De um elogio puro e simples ao texto de Schiller, como se viu na carta de abril, ele passa para uma espécie de crítica. Embora não se possa aqui abordar a outra frente desse projeto, a saber, a relação com o Fedro de Platão, o presente texto procurará desvendar o modo como Hölderlin recepciona o Sobre graça e dignidade de Schiller e em que sentido ele pensava ser possível dar um passo além do projeto kantiano.

\section{O projeto estético de Schiller}

Schiller escreve o ensaio Sobre graça e dignidade nos meses de maio e junho de 1793 e publica o texto na Neue Thalia no próprio mês de junho. No que se refere ao seu projeto de fundação de uma estética objetiva, o Sobre graça e dignidade não traz mudanças substanciais em relação às cartas a Körner (também conhecidas como Cálias, ou sobre a beleza), a não ser num único ponto específico: ao traduzir os conceitos do Cálias - ainda intimamente ligados ao vocabulário kantiano - no par graça e dignidade, Schiller aprofunda a crítica à moral kantiana que já aparecia naquele, embora apenas implicitamente. No Cálias, afinal, a crítica de Schiller não se endereçava tanto à filosofia moral de Kant, e sim mais ao subjetivismo da concepção de beleza da "Analítica do Belo" da Crítica da faculdade do juízo. Por isso, no Cálias, Schiller denominava seu projeto de uma "quarta via" de investigação do belo, em oposição à via "sensível subjetiva" de Burke e dos ingleses em geral, que acabavam por confundir o 
sentimento do belo com um prazer meramente empírico; à via "racional objetiva" de Baumgarten e de Mendelssohn, que reduzia toda a peculiaridade desse sentimento ao próprio prazer intelectual do bom7; e à via de Kant que, apesar de ter "jogado muita luz sobre a natureza do belo" (KS, TS, p. 273) ao encontrar uma via intermediária entre os ingleses e os alemães, permanecia ainda num nível "subjetivo racional".

Seguindo uma via diferente dessas três que o precederam, Schiller declarava a Körner que a sua deveria ser considerada "uma quarta forma possível de esclarecer o belo". Segundo essa sua forma, que aprofundaria e radicalizaria a via "subjetivo racional" de Kant, e que Schiller chama de via "sensível objetiva", deveria ser provado "suficientemente que a beleza é uma propriedade objetiva” (ibid., p. 287). Para isso, Schiller mantém-se rente à argumentação própria do juízo reflexionante da Crítica da faculdade do juízo, especialmente a sua função técnica do como se, que permite estabelecer a harmonia perfeita entre natureza e razão, sem que uma exercesse um poder tirânico sobre a outra e o belo pudesse se apresentar livre de toda e qualquer coerção. Essa retomada de Kant no Cálias fica mais clara quando Schiller investiga a possibilidade de se pensar o belo como aquela representação que se origina no momento em que a razão empresta sua forma à natureza. Segundo Schiller, como a forma da razão é a liberdade, então o belo é aquela representação em que a natureza, por meio

7 Schiller observava já em Sobre o fundamento do prazer em objetos trágicos que, ao tentar mostrar que o fim do belo não é "o frívolo prazer [Vergnügen]", os filósofos teriam colocado as artes numa posição contraditória. "Para atribuir às artes um patamar elevado", escreve, "para conquistar para ela a benevolência do Estado, o respeito de todos os homens", se as expulsou "para fora de seu próprio terreno", e acabou por se as importunar "com um ofício que lhes é estranho e que não pertence à sua natureza” (Über den Grund des Vergnügens an tragischen Gegenstanden, in: TS, p. 235). Em outras palavras, procurando mostrar que o sentimento do belo não pode se confundir com o próprio prazer empírico, os filósofos teriam acabado por submetê-lo inteiramente ao fim moral, como se não restasse à beleza nenhuma outra função a não ser a de conduzir de algum modo à ideia do moralmente bom. Quando, porém, se descobre que a arte não dá inteiramente conta de executar essa tarefa, então se vê nela uma contradição. 
da técnica do juízo, aparece em toda a sua liberdade possível. Nesse caso, a razão "empresta ao objeto [...] uma capacidade de se autodeterminar, uma vontade, e o examina então sob a forma dessa sua vontade" (ibid., p. 284). Por meio desse artifício, a razão atribui à natureza aquilo que pertence à própria razão, a saber, a sua capacidade de autodeterminação (Selbstbestimmung) e, ao fazê-lo, vê na natureza uma semelhança com a liberdade (Freiheitähnlichkeit):

Como, entretanto, essa liberdade é apenas emprestada ao objeto pela razão, pois nada pode ser livre a não ser o suprassensivel, e a própria liberdade nunca pode ocorrer nos sentidos, logo, como se trata aqui apenas de que um objeto apareça livre, não que seja realmente livre, então essa analogia de um objeto com a forma da razão prática não é liberdade de fato, mas apenas liberdade no fenômeno. Autonomia no fenômeno (KS, TS, p. 284-5).

Nesse sentido, a beleza é definida por meio da "analogia de um fenômeno com a forma de uma vontade pura ou com a liberdade", de modo que a "beleza, portanto, não é senão liberdade no fenômeno" (ibid., p. 285). Quando se julga um objeto como belo, a única coisa que se quer realmente saber dele é se ele é aquilo que ele é unicamente por meio de si mesmo, isto é, se não existe nenhum tipo de interferência externa a sua produção. Para ser belo, exige-se que o objeto apareça inteiramente livre de todo e qualquer conceito, regra ou finalidade, o que não significa que conformidade a fins ou regulamentação nada tenham que ver com o belo. Com efeito, "todo produto belo deve se submeter a regras", mas ele deve ao mesmo tempo "aparecer livre de regras" (ibid., p. 289). Do belo, pois, não se exige nada, tal como o faz o imperativo categórico no domínio da razão prática e tal como o fazem os conceitos no âmbito da razão teórica. Pelo contrário, o belo "é uma forma que não exige nenhuma explicação ou então é uma forma que se explica sem conceito" (ibid., p. 291). Uma forma que se explique apenas por meio de conceitos expressa não 
a liberdade no fenômeno, mas a "heteronomia no fenômeno". No conceito, afinal, há sempre algo de externo ao objeto, que o remete ou a sua utilidade ou a sua determinação.

Mas, considere-se esse mesmo problema ainda do ponto de vista da razão prática. Um objeto determinado não por si mesmo, como exige o mandamento schilleriano da beleza, mas por meio da razão prática, representa igualmente uma "heteronomia no fenômeno". Pois se trata, então, de um julgamento moral, e não de um julgamento referente exclusivamente ao belo, no qual a sensibilidade deve falar por si mesma. Segundo Schiller, dado que " $r a-$ zão e sensibilidade possuem vontades diferentes, então a vontade da sensibilidade é rompida quando a razão impõe a sua vontade" (ibid., p. 292). Por isso, quando a razão exerce sua autonomia, que não pode ocorrer nos fenômenos, estes são imediatamente carregados de heteronomia. Não há dúvida de que, para ser belo, um objeto deve estar de algum modo ligado à moralidade e mesmo uma ação moral pode ser considerada bela. Para isso, porém, ela não deve ocorrer por meio de uma coerção (Zwang) do objeto, mas, pelo contrário, "nossa natureza sensível deve aparecer moralmente livre, muito embora ela não o seja em si mesma, e é preciso que tenha a aparência de que a natureza simplesmente executou a tarefa de nossos impulsos" (ibid., p. 296).

Isso mostra que já no Cálias Schiller havia pensado a beleza como livre de todo tipo de coerção, incluindo-se aí a coerção moral. Mas é apenas no Sobre graça e dignidade que essa concepção se transforma numa crítica direta à moral como um todo e em especial à kantiana, o que faz desse escrito um divisor de águas na história da estética ${ }^{8}$. Nesse escrito, Schiller procura sistema-

8 Como escreve Rüdiger Safranski, nesse meio tempo que separa o Cálias do Sobre graça e dignidade, acontece algo determinante para esse acento na crítica à moral iluminista que recebe o último escrito: a condenação à morte de Luís XVI em 21 de janeiro de 1793 em Paris, bem como a invasão de Mainz pelos revolucionários franceses e sua tentativa de instaurar a revolução também nessa cidade. Schiller menciona ambos os fatos na carta a Körner de 28 de fevereiro de 1793 (In: KS, TS, p. 320), imediatamente 
tizar todas essas investigações sobre o belo que ele havia enviado a seu amigo Körner, deixando de lado aquele vocabulário ainda estreitamente ligado a Kant, próprio do Cálias. Schiller procura aplicar sua concepção do belo como algo "objetivo", entendida como "liberdade no fenômeno", em sua definição de graça (Anmut): "Graça é a beleza da forma sob a influência da liberdade" (AW, TS, p. 344), isto é, um objeto ao qual a razão empresta sua forma. Na própria graça, entretanto, é ainda possível distinguir a beleza arquitetônica, referente à sua mera forma, e a própria sensibilidade, isto é, tudo aquilo que não é um produto de nossa intenção, arbítrio e razão. Mas somente é gracioso um objeto em que razão e natureza estão em cooperação, isto é, em que a natureza é espiritualizada e o espírito, naturalizado. Com isso, Schiller procura superar o dualismo entre razão e sensibilidade sem precisar recorrer ao imperativo categórico e toda sua carga coercitiva em relação à sensibilidade. Afinal, diz Schiller, se a razão prática comporta-se sempre de modo coercitivo e violento em relação à sensibilidade, é impossível preservar qualquer graça. Dito de outro modo, caso se considere a moral tal como em Kant, a influência da liberdade na natureza jamais pode ser graciosa:

$\mathrm{Na}$ filosofia moral kantiana a ideia de dever [Pflicht] é apresentada com uma rigidez tal que toda graça é espantada e um fraco entendimento poderia facilmente tentar procurar a perfeição moral no caminho de uma ascese obscura e monástica (ibid., p. 367).

A referência a um tema religioso aqui não é simples acaso, evidenciando ainda que a obra de Kant a que Schiller se refere não é a Crítica da razão prática, mas A religião nos limites da simples razão, de 1793. Que se trate efetivamente desta última, e 
não da primeira, é o próprio Schiller quem o confirma na carta a Körner de 28 de fevereiro de 1793: "Em algumas semanas, vou surpreender-te com uma nova obra de Kant [...]. Está sendo impressa aqui e, como já estava pronta, eu já li a metade. O título é: doutrina filosófica da religião [philosophische Religionslehre]" (KS, TS, p. 318). Mas apesar de se revelar entusiasmado com essa nova obra de Kant, Schiller, nessa mesma ocasião, não escondia suas dúvidas quanto à tarefa ali proposta pelo filósofo, de "subsidiar a religião cristã por meio de fundamentos filosóficos”. Como se pode ler na sua carta a Goethe de 17 de agosto de 1795:

O traço característico, peculiar do cristianismo, que o diferencia de todas as religiões monoteístas, repousa justamente na supressão da lei [Aufhebung des Gesetzes] ou do imperativo kantiano, em cujo lugar o cristianismo deseja ter colocado uma inclinação livre. Portanto, em sua forma pura, ele [o Cristianismo] é uma exposição da bela moralidade ou da apropriação humana do sagrado, e nesse sentido ele é a única religião estética ${ }^{9}$.

Segundo Schiller, esse caráter estético da religião cristã perde-se necessariamente no rigorismo ascético e monástico da concepção kantiana de dever ${ }^{10}$. A moralidade, nesse sentido, não pode ser apenas coercitiva e dominadora em relação à sensibilidade, caso se pretenda de fato dissolver a dualidade, o abismo que há entre uma e outra. A moral deve ser bela, no sentido de que deve levar em conta também a particularidade do objeto, e não apenas a universalidade da lei ${ }^{11}$. Daí a insistência de Schiller

9 Apud Janz, R.P. In: Schiller, F. Theoretische Schriften, 2008, p. 1337-8.

10 Segundo aponta Márcio Suzuki (In: Schiller, F. A educação estética do homem, 1989, p. 16): “Trata-se, portanto, de não perder de vista o 'espírito' do sistema que se quer construir, evitando a unilateralidade de uma 'moral demoníaca' fundada exclusivamente no imperativo categórico, no ascetismo de uma 'vontade santa' que obedeceria incondicionalmente à razão".

11 Anos mais tarde, Hegel reconheceria a importância dessa ideia de Schiller no que se refere à "natureza do ideal artístico", que "deve ser procurada nesta recondução da existência exterior ao espiritual, de tal modo que o fenômeno exterior, como adequa- 
na natureza humana como uma totalidade: "A natureza humana é um todo mais ligado na realidade do que é permitido ao filósofo, que apenas pode deixá-la aparecer por meio da separação” (AW, TS, p.369). Com efeito, Schiller pretende atacar a moral kantiana também do ponto de vista antropológico, segundo o qual uma moral monástica peca contra essa ideia da natureza humana como um todo indissociável, uma unidade perfeita. Uma moral bela, por sua vez, que leve em conta também a particularidade do objeto só é possível por uma bela alma (schöne Seele), isto é, aquela em que "sensibilidade e razão, dever e inclinação se harmonizam, e graça é sua expressão no fenômeno” (AW, TS, p.371). Afinal, "em uma vida bela, como em uma pintura de Ticiano, todas as linhas limítrofes, separadoras, desaparecem, de modo que o todo da forma surge tanto mais verdadeiro, mais vivo, mais harmônico" (ibid., p.371).

Essa harmonia a que Schiller se refere no exame da graça é, entretanto, fadada a desaparecer na segunda parte do seu escrito, destinada ao exame da dignidade (Würde). Diferentemente do que ocorria na categoria da graça, aqui entra em jogo a vontade (Wille), que, segundo Schiller, “é um conceito sublime” (AW, TS, p.374 ${ }^{12}$. Situada entre a legislação da razão e a da sensibilidade, a vontade concorda ora com uma, ora com outra, e depende

do ao espírito, torne-se a revelação deste" (Cursos de estética, 2001, vol. I, p. 168). Para a importância que essa concepção de Schiller tem para a elaboração do conceito de individualidade na Fenomenologia do espírito de Hegel, cf. Werle, M. A. Literatur und Individualität. In: Hegels Phänomenologie des Geistes, 2008, p. 350-68.

12 É evidente que o interesse de Schiller pelo sublime tem em vista uma compreensão filosófica da arte trágica. Num texto do mesmo período denominado Sobre o patético, Schiller escreve que o fim último da arte é "a apresentação do suprassensível, e é sobretudo a arte trágica que o realiza, tornando sensível para nós a independência moral em relação às leis da natureza num estado de afeto"(Apud Machado, R. O nascimento do trágico, 2006, p.55). A poesia trágica realiza perfeitamente essa apresentação do suprassensível ao tomar como fundamento justamente o sublime, que, segundo um texto de Schiller do mesmo ano de 1793, pode ser definido como "um objeto frente a cuja representação nossa natureza sensível sente suas limitações, enquanto nossa natureza racional sente sua superioridade, sua liberdade de limitações; portanto, um objeto contra o qual levamos a pior fisicamente, mas sobre o qual nos elevamos moralmente, i.e., por meio de ideias" (Do sublime, 2011, p. 21). 
inteiramente dela a qual legislação obedecer. À medida, porém, que é considerada uma força moral (moralische Kraft), a vontade deve (soll), em meio às exigências tanto de uma quanto da outra, concordar com a legislação da razão e negar a legislação sensível. Para haver moralidade, a legislação da natureza deve entrar em conflito (Streit) com a legislação da razão e a vontade deve agir de acordo com a segunda e não com a primeira:

Aquele ato da vontade que traz os interesses da faculdade de apetição [Begehrungsvermögen] diante do fórum moral é, portanto, no sentido próprio, contra a natureza [naturwidrig], porque ele torna o necessário [das Notwendige] novamente ocasional, e deixa a critério das leis da razão a decisão de um assunto em que apenas leis da natureza podem se manifestar... (AW, TS, p.377).

Assim como a razão não ousa decidir pelos sentidos o modo como devem tomar suas decisões, a natureza, em sua jurisdição própria, não julga o modo como deve agir a razão. Cada uma dessas jurisdições possui uma necessidade diferente, o que não seria possível caso uma de fato interferisse no domínio da outra, executando aí alterações arbitrárias em favor de si própria. Isso, por outro lado, não impede ao "espírito mais ousado" resistir à sensibilidade, não propriamente subjugando a sensação ou o desejo, mas recusando-lhe a influência na determinação de sua vontade. É por isso, escreve Schiller, que a moralidade (Sittlichkeit) só pode se revelar por meio de uma resistência (Widerstand) ou de uma contradição (Widerspruch) da vontade em relação à jurisdição da natureza. A consequência é que, nesses casos, não se trata de uma ação "moralmente bela, porque na beleza da ação deve participar necessariamente também a inclinação, que aqui, pelo contrário, é combatida”. Por outro lado, porém, essa ação é "moralmente grandiosa, porque somente é grandioso aquilo que dá testemunho de uma superioridade da faculdade superior sobre a faculdade inferior". Consequentemente, "a bela alma deve 
passar, no afeto, para uma alma sublime e essa é a pedra-de-toque irrefutável que permite diferenciá-la do bom coração ou da virtude do temperamento [Temperamentstugend]" (ibid., p. 378).

Schiller, desse modo, estabelece a definição de dignidade em estreita ligação com a definição de liberdade no fenômeno do Cálias: "Dominação dos impulsos por meio da força moral é liberdade de espírito [Geistesfreiheit] e sua expressão no fenômeno chama-se dignidade" (ibid., p. 378). Em outros termos, quando o espírito se impõe à sensibilidade como seu dominador a expressão desse ato denomina-se dignidade. "No caso da graça, pelo contrário, ele age com liberalidade, porque aqui ele é aquele que põe a natureza em ação e não encontra nenhuma resistência para vencer" (ibid., p. 381). Enquanto "a graça deixa a natureza lá onde ela obedece ao mandamento do espírito", a "dignidade, pelo contrário, submete-a ao que ela quer dominar, o espírito" (ibid., p. 381). E essa é, conclui Schiller, "em poucas palavras, a lei para a relação de ambas as naturezas no homem, tal como ela se expõe no fenômeno" (ibid., p. 382): enquanto a dignidade se expressa pela paixão (Leiden), "pois apenas na paixão a liberdade do ânimo pode se revelar", a graça se expressa pelo comportamento ou hábito (Betragen); a primeira é a expressão do pathos, a segunda, a do ethos.

Muito embora a dignidade se expresse por meio da resistência e da contradição ${ }^{13}$, "o ideal da humanidade perfeita não exige

${ }_{13} \mathrm{O}$ elemento próprio da arte trágica é o sublime justamente na medida em que é por meio da representação das limitações sensíveis proporcionada por ele que o homem se torna capaz de sentir sua superioridade moral, "sua liberdade de limitações" no campo do suprassensível. A tragédia é a arte superior porque, ao se centrar no sofrimento humano, na paixão, ela realiza essa passagem para o moral, estabelece uma ligação com a razão, por meio da qual o homem se sente capaz de superar aquele sofrimento. Para utilizar uma imagem de Kant, o sublime exige que a imaginação exponha uma ideia da razão na sensibilidade, obriga-a a inverter a série temporal da apreensão a que ela estava, por assim dizer, acostumada. Ao ser obrigada a expor uma ideia suprassensível na sensibilidade, a imaginação é levada ao seu extremo, é levada a romper com os limites do entendimento, isto é, com os limites do próprio belo. Caracterizando-se inicialmente pela dor, o sublime é por isso definido como um comprazimento que exige primeiro um sacrifício, uma renúncia da faculdade de 
nenhuma oposição, mas concordância entre o moral e o sensível" (AW, TS, p. 382). A dignidade, porém, não pode por si só garantir a unidade projetada por esse ideal porque, ao se arvorar no dever moral, ela exige sempre da sensibilidade uma ação que esta não pode realizar por ser necessariamente uma faculdade passiva. Por isso, escreve Schiller, a graça se refere a tudo aquilo que o homem deveria fazer no interior da humanidade, enquanto que a dignidade se refere àquilo que está para além dela. Enquanto a primeira se situa no domínio da inclinação (Neigung), a segunda se situa no domínio da virtude (Tugend). Mas, procurando evitar que a inclinação prevaleça sobre a virtude e conduza a "autoatividade do espírito" a um estado de modorra, "é preciso que a inclinação esteja o tempo todo ligada com a dignidade" (ibid., p. 384) num mesmo estado e numa mesma pessoa:

Se graça e dignidade [...] estão unificadas na mesma pessoa, então a expressão da humanidade está nela acabada, e ali ela permanece, justificada no mundo espiritual e livremente revelada no fenômeno. As duas legislações se tocam aqui de um modo tão próximo que seus limites se confundem. Com um brilho suave, a liberdade racional se eleva no sorriso da boca, no olhar brandamente vívido, na alegre testa, e com uma sublime despedida, a necessidade natural se extingue na nobre majestade da face. Os antigos se formaram segundo esse ideal da beleza humana, que se pode reconhecer na forma divina de uma Níobe, no Apolo de Belvedere, no gênio alado de Borghese e na musa do Palácio de Barberine (ibid., p. 385-6).

Essa ideia permite compreender o interesse e a admiração de Hölderlin por esse texto de Schiller. Seus projetos referentes ao Hipérion estão de fato muito próximos desse ideal descrito por Schiller. Mas, antes de compreender como isso se dá, é preciso imperscrutável da faculdade suprassensível que se estende até o imprevisível" (Kant 1998, p. 170; B 120). 
ainda responder à questão: como afinal graça e dignidade se unificam na mesma pessoa, de modo que a expressão da humanidade apresente-se acabada nela? Ou, para usar os termos de Kant: como é possível unificar belo e sublime num mesmo sujeito, sem que um leve à anulação do outro? Schiller responde: por meio do amor. Situado entre o respeito (Achtung) à lei moral e o desejo (Bergierde) puramente sensível, o amor permite uma inclinação do primeiro ao segundo, que os aproxima. "Enquanto o respeito se curva [beugt sich]" e "o desejo se atira [stürtzt auf]", "o amor se inclina [neigt sich] aos seus objetos". Se, no respeito, o objeto é a razão e o sujeito é a natureza sensível e, no desejo, ambos são sensíveis, "no amor, o objeto é sensível e o sujeito é a natureza moral" (AW, TS, p. 288). A partir disso, Schiller conclui que "somente o amor" exprime uma sensação (Empfindung) livre, "pois sua fonte pura flui da sede da liberdade, de nossa natureza divina", de modo que,

aqui, não é o pequeno e inferior que se perde com o grandioso e elevado, não é o sentido que olha com vertigem para cima, para a lei da razão; é a própria grandeza absoluta [absolut Grosse] que se encontra reproduzida na graça e na beleza e se satisfaz na moralidade, é o próprio legislador, o Deus em nós, que joga com sua própria imagem no mundo sensível (ibid., p. 388-9).

Por meio do amor, a razão volta-se ao seu oposto, à sensibilidade, não para dominá-la, mas para encontrar nela seu próprio reflexo, sua própria imagem, e jogar com ela livremente. O amor, assim, permite a dissolução dos rígidos limites da razão e da sensibilidade, sem que eles desapareçam completamente ${ }^{14}$. Com isso,

${ }_{14}$ Cf. Henrich, D. Hegel im Kontext, 2010, p.12-7. Segundo Henrich, é importante situar essa concepção de Schiller sobre o amor na tradição da disputa entre a concepção platônica de Hemsterhuis e a aristotélica de Herder. Enquanto o primeiro defendia o amor como entrega (Hingabe) e dissolução do eu no exterior, o segundo defendia que o amor tem necessidade de uma limitação no eu (Selbst), sem o que ele não 
Schiller atinge o que ele próprio havia declarado ser a essência da religião cristã como um todo, a saber, o fato de ela ser uma religião estética. Nela, o homem capaz dessa síntese entre razão e sensibilidade dá vazão ao próprio Deus existente nele.

\section{O projeto de Hölderlin: esboço para uma teoria da imaginação}

A seguinte passagem de A juventude de Hipérion - versão do romance escrita em 1795 durante a estadia de Hölderlin em Jena - mostra com que virulência o poeta foi arrebatado por essa ideia de Schiller acerca do amor como o elemento que sintetiza razão e sensibilidade num homem divino:

Quando nosso espírito [...] desprendeu-se das livres asas do celeste, e se inclinou do éter em direção à terra, quando a abundância desposou a miséria, lá estava o amor. Isso aconteceu no dia em que nasceu Afrodite. No dia em que o belo mundo começou para nós, começou para nós a escassez da vida. Se nós éramos outrora plenos e livres de todos os limites, então não perdemos a plenitude por nada, o privilégio do puro espírito. Trocamos a calma livre de sofrimento dos deuses pelo sentimento de vida, pela clara consciência. Pense, se for possível, o espírito puro! Ele não lida com a matéria; por isso não vive para ele nenhum mundo; para ele nenhum sol se levanta ou se põe; ele é tudo e por isso ele é nada para si. Ele não prescinde, porque ele não pode desejar; ele não sofre, pois ele não vive (HJ, SW I, p. 219-20).

Somente no dia em que nasceu Afrodite, em que o espírito deixou de ser puro e se tornou ao mesmo tempo sensível, "o belo mundo começou para nós", assim como "começou para nós a es-

poderia ser amor. A concepção de Schiller seria uma primeira tentativa de síntese entre essas duas tendências ao procurar ao mesmo tempo definir o amor como um alargamento do eu sem dissolver os limites que o caracterizam. 
cassez da vida". Nesse mesmo momento nasceu o amor: "quando a abundância desposou a miséria”. Segundo a famosa passagem de O banquete de Platão, o amor só é possível se carece de algo, assim como o filósofo só é filósofo se não possui a sabedoria (Platão 1983 , 199a-203 ${ }^{\mathrm{a}}$, p. 30-5). O homem igualmente só conhece o amor ao trocar "a calma livre de sofrimento dos deuses pelo sentimento de vida, pela clara consciência”. E embora se encontrem aqui presentes as ideias de Schiller, Hölderlin ousa dar um passo além dele ao mesmo tempo em que procura também ultrapassar o limite kantiano. No fragmento citado, afinal, o poeta busca pelo momento da origem da cisão, o momento em que "nosso espírito [...] desprendeu-se das livres asas do celeste, e se inclinou do éter em direção à terra". Que momento foi esse? É possível determiná-lo filosoficamente?

Para respondê-lo, é imprescindível retornar ao ano de 1792, em que Hölderlin escreve o Hino à beleza (Hymne an die Schönheit). Segue uma tradução literal e em versos brancos, sem nenhuma pretensão literária, das primeiras cinco estrofes da segunda versão:

\section{Hino à beleza}

Em suas belas formas, a natureza fala a nós de modo figurado e o dom de interpretação de seu escrito simbólico é dado a nós no sentimento moral (Kant).

Não jurou minha alma para ti

Fidelidade, musa encantadora!, Diante dos ouvidos de todos os deuses,

Até os Portões de Orkus?

Não riem teus olhos para mim?

Ah! Assim peregrino eu sem tremor,

Por meio do amor livre e corajoso,

Em direção às alturas austeras,

Onde em vida eternamente jovem

Florescem coroas para o poeta.

Reinando além de Órion, Onde o som do polo se esvai,

\section{Hymne an die Schönheit}

Die Natur in ihren schönen Formen spricht figürlich zu uns, und die Auslegungsgabe ihrer Chiffernschrift ist uns im moralischen Gefühl verliehen (Kant).

Hat vor alle Götter Ohren Zauberische Muse! dir Treue bis zu Orkus Toren Meine Seele nicht geschworen?

Lachte nicht dein Auge mir?

Ha! So wall' ich ohne Beben,

Durch die Liebe froh und kühn, Zu den ernsten Höhen hin, Wo in ewig jungem Leben

Kränze für den Sänger blüh'n.

Waltend über Orionen, Wo der Pole Klang verhallt, 
Riam demônios perfeitos

Para louvar do serviço clerical,

A beleza em sua forma original;

Para me banhar ali no brilho,

Para me aproximar ali da criadora,

Inunda-me o desejo orgulhoso,

Pois com altos encantos da vitória

Compensa ela a corajosa via.

Entusiasmos mais puros

Bebe já a livre alma;

Os lamentos de minha vida

Foram pelo novo prazer tragados,

Noite e névoa fugiram;

Quando num tribunal horripilante

Rapidamente os mundos em pó se fazem -

Aqui a alegria não empalidece,

Onde de sua face

Fala o amor e a grande calma.

Você desce então para a terra,

Rainha, em trajes luzentes!

Ah! As cinzas reavivam,

E a frágil plumagem da aflição

Lança-se na terra do júbilo;

Ao convalescer o olhar pelo amor

Rancor e selvagem desavença

Alegraram-se e beijaram-se fraternalmente;

Jubilosos sentiram todos os seres

A ti em um grau mais elevado.

Já nas verdes proximidades da terra

Experimentei elevado pré-prazer;

$\mathrm{Na}$ boca divina, estremecendo,

Bebi antes da hora da colheita

De ti o doce beijo maternal;

Estranho ao meu sentido infantil

Seguiu-me ao prado e ao bosque

A figura da Arcádia -

Ah! e prostrado fiquei eu

Consciente da magia de seu poder.
Lacht vollendeter Dämonen

Priesterlichen Dienst zu lohnen,

Schönheit in der Urgestalt;

Dort im Glanze mich zu sonnen,

Dort der Schöpferin zu nah'n,

Flammet stolzer Wunsch mich an,

Denn mit hohen Siegeswonnen

Lohnet sie die kühne Bahn.

Reinere Begeisterungen

Trinkt die freie Seele schon;

Meines Lebens Peinigungen

Hat die neue Lust verschlungen,

Nacht und Wolke sind entfloh'n;

Wenn im schreckenden Gerichte

Schnell der Welten Achse bricht -

Hier erbleicht die Freude nicht,

Wo von ihrem Angesichte

Lieb` und stille Grö e spricht.

Stiegst du so zur Erde nieder,

Königin im Lichtgewand"!

Ha! Der Staub erwachte wieder,

Und des Kummers morsch Gefieder

Schwänge sich in's Jubelland;

Durch der Liebe Blick genesen

Freut ' und kü te brüderlich

Groll und wilder Hader sich;

Jubelnd fühlten alle Wesen

Auf erhöhter Stufe dich.

Schon um grünen Erdenrunde

Schmeckt ich hohen Vorgenu;

Bebend dir am Göttermunde,

Trank ich früh der Weihestunde

Sü en mütterlichen $\mathrm{Ku}$;

Fremde meinem Kindersinne

Folgte mir zu Wies' und Wald

Die arkadische Gestalt -

Ha! Und staunend ward ich inne

Ihres Zaubers Allgewalt.

(SW II, p.130-1)

A epígrafe que Hölderlin escolhe para essa segunda versão do poema, uma citação livre do $\$ 42$ da Crítica da faculdade do juízo

de Kant acerca do "interesse intelectual sobre o belo", contribui para a compreensão desse passo além do limite kantiano que está na base de seu projeto sobre as ideias estéticas. Pois essa epígrafe 
não é uma citação literal, tal como se pode ver comparando-a com a passagem da própria Crítica ${ }^{15}$. Como mostrou Paul Böckman, Hölderlin não retirou essa citação do próprio Kant, mas da página de rosto do livro de Friedrich Heinrich Jacobi Allwill Briefsammlung, em sua edição de $1792^{2^{16}}$, cuja carta XVI contém passagens do Fedro, o diálogo platônico preferido de Hölderlin. O trecho a seguir, retirado de A Schlosser sobre a continuação do Banquete platônico de Jacobi, do qual Hölderlin teria tomado a necessidade de ir além do limite kantiano, mostra em que sentido é possível interpretar a modificação da citação de Kant:

Aquilo que em todo ser finito criado liga finito e infinito de uma forma comedida e que traz à luz o ser efetivo por meio da determinação do em si mesmo indeterminado é a alma. Ela se mostra como o princípio da natureza orgânica em todo elemento vivo particular antes de toda experiência sensível [...]. A fome, por exemplo, não reside na própria dor que o animal carente de alimento sente; essa dor é ele próprio, é pura dor, e não contém nenhuma sensação de algo externo a ele [...]. Portanto, a fome pressente, procura e encontra seu objeto como desejo antes de toda experiência sensível, que apenas por meio do desejo é tornada possível, consequentemente este não a poderia ter produzido. Tal como nesse exemplo, também em todo lugar vê-se o desejo - que é o meio primitivo de conhecimento do bom, é sua revelação - para além da sensação; [...] De modo predizente, ele dá à luz experiência e entendimento. Por isso a faculdade de apetição [Begehrungsvermögen] é a própria alma; e toda alma, como aquela que dá a medida, [... é natureza divina ${ }^{17}$.

15 O texto original de Kant diz: "Dir-se-á que esta interpretação dos juízos estéticos sobre a base de um parentesco com o sentimento moral parece demasiado estudada para considerá-la a verdadeira exegese da linguagem cifrada pela qual a natureza em suas belas formas nos fala figuradamente" (Crítica da faculdade do juízo, 1998, p. 204; B170).

16 Cf. Das ,Späte‘ in Hölderlins Spätlyrik. In: Hölderlin-Jahrbuch, 1961-2, p.209 e ss., apud Henrich, D. Der Grund im Bewu tsein, 1992, p. 156.

17 Jacobi, F.H. An Schlosser über dessen Fortsetzung des Platonischen Gastmales, 2007, p. 230-1. 
Esse texto de Jacobi ajuda a interpretar a epígrafe do poema de Hölderlin da seguinte forma: segundo essa concepção de alma de Jacobi, a ligação entre o finito e o infinito não é realizada no exterior, mas interiormente. Ao se considerar essa relação do ponto de vista da alma, é possível atingir a origem da própria experiência sensível, da qual o desejo é a expressão. Quando Kant se refere ao fato de que a natureza fala de modo cifrado com o homem por meio de suas belas formas, e que ao homem é dado o dom de sua interpretação por meio do sentimento moral, isso é lido no sentido de que ao homem é dado o dom de atingir o momento anterior à experiência sensível. Esse momento é o próprio sentimento moral que, como se viu em Sobre graça e dignidade, deve voltar-se para a natureza e ver nela sua própria imagem. Ao elevar-se ao sentimento moral - que equivale então àquilo que Jacobi chama de alma -, o homem é capaz de regredir ao momento "puro" em que a razão está apartada da sensibilidade e de observar aí o nascimento de uma nova ligação, com as formas belas da natureza, que se dá, por assim dizer, pelo interior. Por meio desse regresso, razão e sensibilidade deixam de ser dois objetos exteriores um ao outro, pois a ligação ocorre antes da exteriorização tanto de um quanto do outro. Mostrando-se em toda sua qualidade divina, o sensível se apresenta impregnado de espirituosidade e o espírito prenhe de matéria.

Essa ideia, apenas indicada pela epígrafe, é expressa pelo poema de modo mais claro. Ele pode ser dividido em duas partes: da primeira à terceira estrofe, em que o poeta procura expor a relação entre razão e sensibilidade por meio da doutrina platônica das ideias - como uma ascensão do mundo sensível para o inteligível -; e a segunda da quarta estrofe, em que o poeta procura inverter essa hierarquia, mostrando o oposto, a via do mundo inteligível para o sensível (conforme Schiller procurava pensá-la em Sobre graça e dignidade) até o final.

A primeira parte, portanto, segue à risca a doutrina de Platão, mostrando que as ideias eternas - o bom, o verdadeiro e o belo - são 
formas originárias (Urgestalten) fixadas em um lugar elevado, para além de todos os fenômenos cósmicos. Hölderlin descreve essas formas já no verso 11, quando escreve: "Reinando além de Órion/ Onde o som do polo esvai" ("Waltend über Orionen/ Wo der Pole Klang verhallt"). Por essas formas originárias anseia o espírito humano, impulsionado pela força de Eros: "Ah! Assim peregrino eu sem tremor,/ Por meio do amor livre e corajoso,/ Em direção às alturas austeras" "Ha! So wall'ich ohne Beben/ Durch die Liebe froh und kühn,/ zu den ernsten Höhen hin..."). O tema é o movimento ascendente (Aufstieg) do mundo terreno ao mundo das ideias. $\mathrm{Na}$ quarta estrofe, porém, essa ascensão dá lugar a uma queda (Abstieg) do mundo ideal para o mundo real, que não é vista como algo negativo, mas como o momento em que aquela forma originária se transforma para o poeta numa forma bela da natureza, atingindo o passo final de sua perfeição: "Você desce então para a terra,/ Rainha, em trajes resplandescentes" ("Stiegst Du so zur Erde nieder/ Königin im Lichtgewand'!)", lê-se no início da quarta estrofe.

Quando, a partir da quinta estrofe, o poeta menciona ter experimentado o elevado pré-prazer (Vorgenuss) da beleza eterna, ele indica que, como poeta, foi-lhe possível atingir aquela forma originária (Urgestalt), em sintonia com a suposta citação de Kant que serve de epígrafe ao poema, de que é dado ao homem (ao poeta) o dom (Gabe) de interpretar o escrito figurado da natureza num patamar anterior àquele em que ele se encontra efetivamente, na forma originária do sentimento moral. Ao se elevar à moralidade, ao mundo inteligível do suprassensível, o poeta atinge aquele momento anterior à experiência sensível de que fala Jacobi, o momento da Urgestalt, no qual propriamente se origina a ligação com o sensível. Não é ocasional que o poeta ("der Sänger”) opere essa mudança, essa alternância da via ascendente para a descendente e vice-versa ${ }^{18}$, tal como aponta Hölderlin já 
na primeira estrofe: "Assim peregrino eu sem tremor,/ Por meio do amor livre e corajoso,/ Em direção às alturas austeras,/ Onde em vida eternamente jovem/ Florescem coroas para o poeta" ("So wall' ich ohne Beben,/ Durch die Liebe froh und kühn,/ Zu den ernsten Höhen hin,/ Wo in ewig jungem Leben/ Kränze für den Sänger blüh'n”). O poeta detém esse dom especial de atingir o momento originário da ligação entre sensível e inteligível, pois há algo nele que lhe permite usufruir da beleza antes mesmo de seu tempo de colheita, como se pode ler na última estrofe: "Na boca divina, estremecendo,/ Bebi antes da hora da colheita/ De ti o doce beijo maternal" "Bebend dir am Göttermunde,/ Trank ich früh der Weihestunde/ Sü en mütterlichen Ku “).

Também no que se refere ao amor é possível medir a diferença entre as concepções de Hölderlin e as de Schiller. Pois, enquanto este procura apenas mostrar que o amor é o elemento intermediário que permite a conexão entre graça e dignidade, natureza e liberdade, Hölderlin procura pensar essa relação a partir de sua origem. Segundo ele, o amor é capaz de unir as duas instâncias justamente por nascer da queda, vista como o momento originário em que a divindade desce pela primeira vez à terra e se torna real. Se o poeta, assim, consegue atingir a forma originária da beleza por meio do amor, é porque ele é capaz de atingir o momento da sua origem. Esse momento coincide com a queda, em que o inteligível desce ao sensível, o divino ao mortal, e, nessa passagem, ele vê nascer o mundo e o eu, assim como o amor que une um ao outro. Por isso é que no chamado discurso de Atenas Hipérion diz ter sido Heráclito quem melhor capturou a essência da beleza, pois ele também possuía esse dom de regredir até o pré-prazer, próprio da forma originária: "a grandiosa frase de Heráclito, hèn diaphéron heautôi [o uno diferente em si mesmo] só

que é o mais inferior, até o do general que, no meio da batalha, se apodera imponente da clareza de pensamento do gênio, há uma escala infinita. Subir e descer por ela é o talento e a glória do poeta" (SW I, p. 519). 
poderia ser encontrada por um grego, pois é a essência da beleza e, antes de ter sido encontrada, não havia filosofia alguma" (HEG, 2003, p.85).

Como é possível, então, ao poeta atingir esse momento originário da beleza, sua Urgestalt? Qual é esse dom que lhe permite regredir até a origem da consciência e, consequentemente, do próprio mundo? A resposta está em um fragmento dessa mesma época, intitulado Sobre a lei da liberdade. Visto por alguns ${ }^{19}$ como o esboço daquele texto prometido a Neuffer como um comentário sobre o Fedro de Platão, que versaria sobre as ideias estéticas de Kant, esse fragmento indica que Hölderlin procurava pensar o dom do poeta justamente por meio de dois elementos que Schiller não menciona em Sobre graça e dignidade: a imaginação e o gênio-poeta. No Sobre a lei da liberdade, Hölderlin retoma a concepção de Kant segundo a qual o gênio-poeta é aquele por meio do qual "a natureza dá a regra à arte", justamente porque, no gênio, a imaginação atua de forma radical, isto é, em sua máxima capacidade criadora. Mas, como Hölderlin pretende "dar um passo além do limite kantiano", ele concede uma importância ainda maior à imaginação do que o próprio Kant. Segundo seu texto, a imaginação seria não apenas o ponto em que sensível e inteligível se unem, mas a possível origem de ambos. Assim escreve o poeta na primeira parte do fragmento:

Há um estado de natureza [Naturzustand] da imaginação que tem algo de comum com a anarquia de representações que o entendimento organiza, a saber, a ausência de leis, mas que deve ser necessariamente distinguido da lei por meio da qual esse estado deve ser ordenado.

Por esse estado de natureza da imaginação, por essa ausência de lei, en-

19 Cf. Strack, F. Ästhetik und Freiheit. Hölderlins Idee von Schönheit, Sittlichkeit und Geschichte in der Frühzeit, 1976, p. 27-34; Hegel, H. Isaak von Sinclair zwischen Fichte, Hölderlin und Hegel, 1971, p. 31-2. 
tendo a ausência da lei moral e, por esta lei, a lei da liberdade.

Lá a imaginação é examinada em si e para si, aqui em ligação com a faculdade de apetição [Begehrungsvermögen].

Naquela anarquia das representações onde a imaginação é examinada teoricamente era possível na verdade uma unidade do múltiplo, uma ordenação das percepções, mas fortuita.

Nesse estado de natureza da fantasia, onde ela é examinada em ligação com a faculdade de apetição, é na verdade possível uma conformidade à lei moral, mas fortuita (UGF, SW I, p. 496).

Observa-se nesse último parágrafo que Hölderlin escreve não imaginação, mas fantasia, o que não deixa de ser significativo. Embora o fragmento não faça menção à beleza ou mesmo à poesia, o que levou alguns comentadores a afirmar que o texto deveria ser lido como uma incursão de Hölderlin não no âmbito da estética, mas no da filosofia prática, não há como negar que o emprego do termo fantasia aponta para uma investigação da capacidade propriamente poética da imaginação. De algum modo, o uso desse termo deveria ser suficiente para se concluir, diante da escassez do texto, que esses dois estados de natureza da imaginação a que se refere Hölderlin são dois estados propriamente poéticos. Enquanto poeta, o objetivo de Hölderlin ao submeter a imaginação a um escrutínio é, assim como faz Schiller em Sobre graça e dignidade, procurar nela o fundamento filosófico da própria função poética. Mas quais são, então, esses dois estados?

De acordo com o texto, o primeiro estado de natureza (Naturzustand) da imaginação é aquele "que tem algo de comum com a anarquia de representações que o entendimento organiza, a saber, a ausência de lei", e que deve ser distinguido da lei por meio da qual deve ser ordenado, o que o permitiria determinar o segundo estado da imaginação. No que se refere ao primeiro estado de na- 
tureza, portanto, essa faculdade é analisada sem nenhuma ligação com nenhum tipo de lei (“ausência de leis”, escreve Hölderlin), aquilo que confere a esse estado uma característica anárquica. Embora esse primeiro estado de natureza deva ser visto em sua completa "ausência de leis", a referência ao entendimento, logo no início, aponta para o fato de que Hölderlin procura pensar a representação derivada dele de forma semelhante ao modo como Kant pensa o belo na Crítica da faculdade do juízo, em particular no $\int 6$ dessa obra, quando se refere à universalidade sem conceitos proveniente da ligação entre imaginação e entendimento (Kant 1998, p. 99-100; B 17-8). Apesar dessa semelhança, a ênfase de Hölderlin no caráter anárquico próprio desse estado de natureza da imaginação indica que sua concepção de belo não se refere àquela concepção clássica da beleza como harmonia. Nesse texto, Hölderlin se aproxima antes de Friedrich Schlegel, por exemplo, o qual, na Conversa sobre a poesia, põe na boca do personagem Ludovico as seguintes palavras: "a mais elevada beleza, a mais elevada ordem é, justamente, a do caos, um caos que só espera o contato do amor para se desdobrar em um mundo harmônico, um caos como aquele da poesia e da mitologia antigas" (Schlegel 1994 p. 51). Assim como para Schlegel, também para Hölderlin o belo não pode ser separado do divino ${ }^{20}$, do infinito, motivo pelo qual ele aparece pela primeira vez no aórgico, no caótico, justamente ali onde a imaginação se assemelha à anarquia de representações organizada pelo entendimento.

Ainda nesse primeiro estado de natureza, em que a imaginação é examinada "em si e para si”, Hölderlin afirma que esse exame é teórico e que a imaginação pode ocasionalmente produzir uma "unidade do múltiplo", isto é, "uma ordenação das percepções". Como, porém, trata-se de um estado de natureza da imagi- 
nação e não de um estado em que ela seja determinada ou pela lei da razão ou pelo conceito do entendimento, isto é, como se trata de um estado em que ela tem algo de comum com a anarquia das representações que o entendimento organiza, essa unidade do múltiplo a que ela pode porventura chegar não deve jamais ser tomada como universal e necessária. A ausência de leis própria desse estado leva à conclusão de que, se a imaginação chega aqui a uma unidade do múltiplo, essa unidade deve ser apenas ocasional e fortuita, o que fortalece a hipótese de que a imaginação é analisada aqui em seu sentido poético apenas e não em seu papel teórico ou moral.

Portanto, se o primeiro estado de natureza da imaginação corresponde ao belo, o segundo deve corresponder ao sublime, dado que a imaginação é examinada não em ligação com o entendimento, mas sim com a lei moral, a lei da liberdade. Como mostrado acima, é nesse ponto que Hölderlin passa a chamar a imaginação de fantasia, o que não é ocasional. Pois, se é possível dizer que já no primeiro aspecto a imaginação está operando poeticamente (no que se refere ao belo), o fato de Hölderlin inserir o termo fantasia justamente ao tratar do segundo estado de natureza da imaginação indica que ele está se referindo à arte poética. Como se viu pelo texto de Schiller sobre a graça e a dignidade, o sublime é o terreno propício para o desenvolvimento da arte trágica porque, nesse caso, a sensibilidade desperta a lei da razão, de caráter moral. Ao escrever que "nesse [segundo] estado da fantasia, onde ela é examinada em ligação com a faculdade de apetição, é na verdade possível uma conformidade à lei moral", Hölderlin procura pensar de que maneira o sentimento do sublime pode ser considerado o produto da imaginação em um dos seus possíveis estados de natureza e, nessa medida, é de se esperar que ele ligue a isso uma investigação sobre a arte trágica, o que ele não faz nesse fragmento.

O fato, em todo caso, é que, assim como ocorria no seu primeiro estado de natureza, também no segundo, ao ser examina- 
da em sua ligação com a faculdade de apetição, ou faculdade de desejar ${ }^{21}$, a imaginação não produz nenhuma ligação necessária e universal com a lei. Se isso ocorresse, então ela não seria poética, mas estaria sendo analisada para efeitos da filosofia prática. Desse modo, embora nesse segundo estado de natureza também seja possível ocorrer uma adequação com a lei moral, essa adequação é igualmente fortuita. E o modo como Hölderlin continua o fragmento aponta para o fato, num tom já conclusivo, de que tanto um estado quanto outro da imaginação permitiriam ao poeta atingir a faculdade de apetição, não em seu momento puro, mas empírico:

Há um aspecto da faculdade de apetição empírica que forma uma analogia particularmente notável com aquilo que se chama natureza, onde o necessário parece se irmanar com a liberdade, o condicionado com o incondicionado, o sensível com o sagrado, lá onde aparece uma inocência natural, poder-se-ia dizer, uma moralidade do instinto, e onde a fantasia que lhe faz eco é celeste.

Mas esse estado de natureza depende como tal das causas naturais.

Ser dessa forma concordante é uma sorte pura e simples (UGF, SW I, p. 497).

O termo "faculdade de apetição empírica" é de difícil compreensão, dado que Hölderlin não o define e dado que também Kant não faz menção a ele nem na Crítica da razão prática, nem

21 Ao fazer menção à faculdade de apetição [Begehrungsvermögen], Hölderlin segue a definição de vontade do próprio Kant, tal como, por exemplo, se pode ler na Crítica da faculdade do juízo: "A vontade, como faculdade de apetição, é nomeadamente uma de entre muitas causas da natureza no mundo, nomeadamente aquela que actua segundo conceitos e tudo o que é representado como possível (ou como necessário) mediante uma vontade chama-se, de um ponto de vista prático, possível (ou necessário)" (Kant 1998, p. 52; B XII). 
na Crítica da faculdade do juízo. Pode-se interpretá-lo como o mero sentimento moral ou aquilo que Kant denomina também de "disposição ao sentimento para ideias (práticas)" (Kant 1998, p. 163; B 112) e que pode ser visto com mais nitidez no sentimento do sublime. Ao elevar o sujeito a esse sentimento para ideias práticas (moral), a imaginação, em um de seus estados de natureza, o conduz a esse patamar originário da representação (poética), isto é, ao momento em que ela é criada no ânimo. Por ser uma representação poética, essa sua criação no ânimo não deve ser tomada no sentido forte do termo. Kant já havia mostrado em diversos lugares que a imaginação, apesar de ser "ou poética (produtiva), ou meramente evocativa (reprodutiva)", "não é criadora", no sentido de que "não é capaz de produzir uma representação sensível que nunca foi dada à nossa faculdade de sentir" (Kant 2006, p.66 (\$ 28). Antes, ao elevar o sujeito ao sentimento moral, ela permite a ele vislumbrar a origem da representação, mas apenas de acordo com o procedimento meramente analógico da imaginação, num sentido próximo àquele do $\$ 59$ da Crítica da faculdade do juízo. (Kant 1998, p. 163; B 112).

Os estados de natureza da imaginação correspondem então a esse plano do sentimento moral que, justamente por ser "anterior" à experiência sensível, permite a realização de uma analogia "notável" entre natureza e liberdade, em que o necessário se irmana com a liberdade, o condicionado com o incondicionado e o sensível com o sagrado. Em outros termos, esses estados de natureza da imaginação elevam o homem ao patamar "divino", no sentido de que ele se torna capaz de criar o sensível e o inteligível analogicamente.

Em Sobre a lei da liberdade, Hölderlin faz referência ao conceito de "liberdade no fenômeno", bem como à definição de homem divino, de Schiller. Mas procura fazê-lo indo além do limite kantiano em que Schiller se deteve, ou seja, procurando atingir a origem dessa representação de liberdade no fenômeno na imaginação poética. Para isso, é muito provável que Hölderlin tenha se 
servido das investigações de Jacobi que, como se viu acima, situava a alma (o ponto de ligação entre finito e infinito) no mesmo patamar do desejo, isto é, no da faculdade de apetição empírica, que antecede toda experiência sensível. Assim como ocorria com o desejo de Jacobi, em suas palavras "o meio primitivo de conhecimento do bom”, também esses estados de natureza da imaginação de que fala Hölderlin se tornam "sua revelação", isto é, mostram-se "como o princípio da natureza orgânica em todo elemento vivo particular antes de toda experiência sensível”. Enquanto tal, esses estados de natureza da imaginação são "aquilo que em todo ser finito criado liga finito e infinito de uma forma comedida" e, "de modo predizente", "dá à luz experiência e entendimento". Por isso, segundo Jacobi, "a faculdade de apetição é a própria alma; e toda alma, como aquela que dá a medida, [...] é natureza divina" (Jacobi 2007, p. 230-1).

Mas o fragmento Sobre a lei da liberdade traz uma outra conclusão essencial. Segundo Hölderlin, para que a analogia entre liberdade e natureza ocorra de fato é necessário que a concordância entre a fantasia e a faculdade de apetição (empírica) ocorra por meio da lei da liberdade, o que permite que a representação gerada por essa concordância (a própria analogia) mantenha-se num estado fixo e duradouro:

Não fosse a lei da liberdade aquela sob a qual a faculdade de apetição se junta à fantasia, então não haveria nunca um estado fixo que fosse semelhante àquele que acabamos de evocar, e de todo modo não dependeria de nós mantê-lo. Seu oposto poderia ocorrer sem que pudéssemos evitá-lo (UGF, SW I, p. 497).

Se a imaginação poética cria, em seus dois estados distintos de natureza, uma analogia da representação do belo com a do sublime, ela o faz de modo absolutamente livre. No primeiro caso, ela é livre porque não é coagida por nenhuma lei, nem do entendimento, nem da razão, e, no segundo, porque entra em 
acordo com a faculdade de apetição (empírica) por meio da lei da liberdade. E, muito embora não se possa negar que a lei da liberdade traga em si uma coerção, como diz Hölderlin "a lei da liberdade exige [bietet] sem nenhuma outra consideração a ajuda da natureza”, essa sua exigência é antes um pressuposto, baseado inteiramente na liberdade, de "uma resistência da parte da natureza, se não ela não exigiria”. Se há uma exigência, é porque a lei da liberdade supõe na própria natureza a liberdade de uma oposição a ela. Como essas duas exigências são unidas na faculdade de apetição empírica por meio da fantasia, elas não se excluem mutuamente. Pelo contrário, são postas lado a lado numa analogia. Por isso, diz Hölderlin mais adiante, "a primeira vez que a lei da liberdade se expressa para nós ela aparece como punição", de modo que "o começo de toda a nossa virtude se dá a partir do mal" (UGF, SW I, p. 497)22. A primeira vez que a lei da liberdade se expressa para nós é como uma forma de correção da transgressão do limite dessa liberdade pela natureza, o que leva Hölderlin a afirmar que "a moralidade, portanto, jamais pode ser confiada à natureza". Se assim fosse, a moralidade não teria nenhuma constância, "tornando-se uma coisa volúvel segundo o tempo e as circunstâncias".

\section{Bilbiografia}

BEISSNER, F. Hölderlins Hymne an das Schicksal. In: "Hölderlin”. Köln, Wien: BÖhlau Verlag, 1969.

HEGEL, H. Isaak von Sinclair zwischen Fichte, Hölderlin und

22 Este gancho permite interpretar no mesmo sentido o fragmento Sobre o conceito de punição (Über den Begriff der Strafe, In: SW I, p. 499). 
Hegel. Frankfurt am Main: Vittorio Klostermann, 1971.

HENRICH, D. Der Grund im Bewusstsein - Untersuchungen zu

Hölderlins Denken (1794-1795). Stuttgart: Klett-Cotta, 1992.

Hegel im Kontext. Frankfurt am Main: Suhrkamp, 2010.

HÖLDERLIN, F. Hipérion ou o eremita na Grécia. Trad. de Erlon José Paschoal. São Paulo: Nova Alexandria, 2003.

. Sämtliche Werke und Briefe. Hg. von Jochen Schmidt.

Frankfurt am Main: Deutscher Klassiker Verlag, 1992.

JACOBI, H. F. An Schlosser über dessen Fortsetzung des Platonischen Gastmales. In: Werke, vol. 5/1, Kleine Schriften II, 1787-1817. Org. Catia Goretzki e Walter Jaeschke. Felix Meiner, Frommann-Holzbog, 2007.

KANT, I. Antropologia de um ponto de vista pragmático. Trad. de Clélia Aparecida Martins. São Paulo: Iluminuras, 2006.

Crítica da faculdade do juízo. Trad. de António Marques e Valério Rohden. Lisboa: Imprensa Nacional Casa da Moeda, 1998.

MACHADO, R. O nascimento do trágico: de Schiller a Nietzsche. Rio de Janeiro: Jorge Zahar, 2006.

PLATÃO. O Banquete. Trad. de José Cavalcante de Souza. São Paulo: Abril Cultural, 1983.

SCHILLER, F. A educação estética do homem. Numa série de cartas. Trad. de Roberto Schwarz e Márcio Suzuki. São Paulo: Iluminuras, 1989 .

Do sublime ao trágico. Trad. de Pedro Süssekind e Vladimir Vieira. Belo Horizonte/São Paulo: Ed. Autêntica, 2011.

Über Anmut und Würde. In: Theoretische Schriften.

Frankfurt am Main: Deutscher Klassiker Verlag, 2008.

Über den Grund des Vergnügens an tragischen Ge-

genstanden. In: Theoretische Schriften. Frankfurt am Main:

Deutscher Klassiker Verlag, 2008.

SCHLEGEL, F. Conversa sobre a poesia. Trad. de Victor-Pierre

Stirnmann. São Paulo: Iluminuras, 1994. 
STRACK, F. Ästhetik und Freiheit. Hölderlins Idee von Schönheit, Sittlichkeit und Geschichte in der Frühzeit. Tübingen: Max Niemeyer Verlag, 1976.

WERLE, M. A. Literatur und Individualität. Zur Verwirklichung des Selbstbewusstseins durch sich selbst. In: Hegels Phänomenologie des Geistes. Ein kooperativer Kommentar zu einem Schlüsselwerk der Moderne. Org. Klaus Vieweg e Wolfgang Welsch. Frankfurt am Main: Suhrkamp, 2008 